atten.ion to the subject, might be able to establish satisfactorily the true cause or causes of a symptom which is so remarkable that I am sure anyone who has met with it in his prac ice will agree with Dr. O'Neill in saying "it has only once to be seen to be for ever remembered." Those to whom I have spoken concerning it appear not to know anything about it, and the only thing left for ine is to bring the matter under your notice.

I am, Sir, your obedient servant, A. Ross Paterson, M.D., M.R.C.P. Edin. Mareham-le-Fen, Dec. 30th, 1882.

\section{"LARGE ASYLUMS FOR THE INSANE."}

To the Editor of THE LANCET.

SIR,-I am greatly gratified by the support given by Dr. S. W. D. Williams to the views I have expressed on the above subject. Dr. Williams's large experience and earnest efforts in improving the condition of lunacy accommodation make his opinion on this point most valuable. Dr. Williams has, however, misapprehended me in thinking I would wish to bave 600 acute cases in one asylum; 600 beds should be the limit for asylums receiving all classes of cases, and this should be the type of most county asylums. Where, however, there are several asylums in a county with a large urban population, as, for example, Middlesex, I should advise a lunatic hospital of not more than 300 beds; 250 would probably suffice even for Middlesex. In such a hospital only a small portion of the acute forms of insanity should be treated to cure, the remainder shonld only be retained for a few days to determine their fitness for asylum treatment, and the special asylum to which they should be sent. The construction of such a hospital need not be so costly as might be anticipated; the economy would, I believe, be great by increasing the number of cures, by diminishing the duration of treatment, by preventing unfit cases being sent to asylums, by diminishing the number of transfers from one institution to another, and by diminishing the average cost of removals to and from the asylums. Such an institution would also afford an opportunity for the scientific investigation of mental diseases, and their study by intending medical practitioners.

It is a national disgrace that, while the expenditure for the cure of the insane has been so great, so little has been spent in the scientific investigation of their diseases, by which means alone can be ensured the most advantageous application of this expenditure. This function might wisely be added to the services rendered by such a hospital.

January, 1883. I am, Sir, your obedient servant,

\section{To the Editor of THE LANCET.}

SIR,-An experience of twenty-nine years in two county asylums has convinced me that Drs. Rayner and Williams are right in their condemnation of gigantic asylums for the insane, on the grounds stated by them. In such enormous and unwieldy establishments it is quite impossible for the superintendent to be conversant with details, and, in my opinion, no asylum should contain more than 600 beds. If this number is exceeded no superintendent can be thoroughly acquainted with every individual case. $\mathrm{He}$ is, then, in the position of a priest with the care of two or three thousand souls, or a shepherd over a flock of several thousant sheep. He is compelled to deal with them en masse. When .we bear in mind that the Commissioners in Lunacy, with their long and vast experience, have arrived at the same conclusions as ourselves, and have recommended changes in accordance with them, it is certainly much to be regretted that they have not the power to enforce them. Taking 600 as the maximum number of inmates, I quite agree with Dr. Williams that these should not all be acute and recent cases. Such an arrangement would necessitate an increased staff, many medical extras, and a vast additional expenditure. Moreover, the concentration and association of so many noisy, excited patients would make their proper treatment insuperably difficult, and tend to convert an asylum into a pandemonium. At Thorpe we have, in connexion with the parent asylum, and on the same estate, an auxiliary asylum, which relieves us of some of our confirmed chronic cases; and this arrangement we find both nseful and economical.
If the capiration grant were extended to harmless lunatics in workhouses, and if proper arrangements were made (e. g., better dietary and a proper staff) there is no doubt that many patients who are now sent to lunatic asylums might, and would, be equally well treated in the workhouse. They would then be nearer to their homes and to their relarions and friends, who could visit them with nut incon. venience and expense, and the county be spared the costly sums expended from time to time in enlarging asylums. It is also absurd that many patients (paralytica, dementia, \&c.) are sent to an asylum as insane who simply require the nursing and attention which the infirmary of a workhouse ought to be able to give.

I am, Sir, yours faithfully,

Willtam C. Hilst, M.D.

Norwich, Jan. 6th, 1883 . Medical Superintendent, Norfolk County Asylum,

\section{OVARIOTOMY STATISTICS. To the Editor of THE LANCET.}

SIR,-I entirely agree with your opinion that the figures are as yet too small to enable us to form an absolute com. parison on any one point. But there is a still greater element of difficulty which is strikingly revealed to me by an investigation of the discrepancies between Mr. Thornton's rendering of Dr. Keith's figures and my own.

Apparently, Mr. Thornton and I have no kind of agree. ment as to what is an "oöphorectomy" and what is an "ovariotomy." Our methods of tabulation are wholly different. I publish all the cases of abdominal section which I perform, in order of date, leaving my eritics to arrange them as they see fit, reserving the same right to myself. Mr. Thornton seems to include in his lists of "ovariotomies" cases of parovarian cysts, and seems to have had no tubal cysts at all. These latter are far more akin to "ovario. tomies " in their difficulties and dangers than are parovarian eysts. When discussing the treatment of the pedicle, which seems to me by far the most important point in dealing with pelvic tumours, I class together naturally all the cystic growths to which I have applied the ligature or the clamp, including some which it would be wholly impossible to classify, as I do not know to this day whence the tumours arose, the patients having been fortunately spared the necessity of a post-mortem examination. The resurrection case seems, so far as I can make out, to arise from Mr. Thornton having included, in the list he bas made for me, two fatal cases of incomplete or extra-perituneal operation, for which I substitute one death of a doubtful nature in which the cautery was used. Until we have a perfect understanding as to our methods of tabulation, it is clearly impossible to derive any satisfactory conclusions from the contrast of the statisties of one surgeon with those of another. Each must form his opinions on any point by contrasts derived from his own experience, and the profession must, as usual, be governed by the weight of authority. In which direction authority will go concerning Listerism, time will tell. I am, Sir, yours truly,

Birmingham, Jan. 13th, 1883.

LAWSON TAIT. En. L.

\section{BRITISH MEDICAL BENEVOLENT FUND.}

\section{To the Editor of THE LANCET.}

SIR,--In connexion with the annual general meeting of the above fund will you permit me through your columns to appeal, first, to the honorary local secretaries, through whose exertions so large a proportion of the contribations to the fund is collected, to send in their lists to the hon. financial secretary, Mr. G. Field, 31, Lower Seymour-street, as soon as possible; secondly, to the subscribers generally, that they will tracsmit, with as little delay as need be, their subscriptions, and especially subscriptions in arrear, to the hon. financial secretary or myself, or to the local representative of the fund. More thnn one-fourth of the sub-crip ins for the last year and for many preceding years remain unpaid, and we are in this predicament, either we most drop the names out of the published Jist, and so displease many who have no int 6 nion of deserring the charity, or we mustretain all names in the absence of an intimstion that a subscription 